Review Article

\title{
Neural Vascular Mechanism for the Cerebral Blood Flow Autoregulation after Hemorrhagic Stroke
}

\author{
Ming Xiao, ${ }^{1}$ Qiang Li, ${ }^{2}$ Hua Feng, ${ }^{2}$ Le Zhang, ${ }^{3}$ and Yujie Chen ${ }^{2}$ \\ ${ }^{1}$ College of Computer and Information Science, Southwest University, Chongqing, China \\ ${ }^{2}$ Department of Neurosurgery, Southwest Hospital, Third Military Medical University, Chongqing, China \\ ${ }^{3}$ College of Computer Science, Sichuan University, Chengdu, China
}

Correspondence should be addressed to Le Zhang; zhanglcq@swu.edu.cn and Yujie Chen; yujiechen6886@foxmail.com

Received 30 June 2017; Accepted 11 September 2017; Published 26 September 2017

Academic Editor: Sheng Wang

Copyright (c) 2017 Ming Xiao et al. This is an open access article distributed under the Creative Commons Attribution License, which permits unrestricted use, distribution, and reproduction in any medium, provided the original work is properly cited.

During the initial stages of hemorrhagic stroke, including intracerebral hemorrhage and subarachnoid hemorrhage, the reflex mechanisms are activated to protect cerebral perfusion, but secondary dysfunction of cerebral flow autoregulation will eventually reduce global cerebral blood flow and the delivery of metabolic substrates, leading to generalized cerebral ischemia, hypoxia, and ultimately, neuronal cell death. Cerebral blood flow is controlled by various regulatory mechanisms, including prevailing arterial pressure, intracranial pressure, arterial blood gases, neural activity, and metabolic demand. Evoked by the concept of vascular neural network, the unveiled neural vascular mechanism gains more and more attentions. Astrocyte, neuron, pericyte, endothelium, and so forth are formed as a communicate network to regulate with each other as well as the cerebral blood flow. However, the signaling molecules responsible for this communication between these new players and blood vessels are yet to be definitively confirmed. Recent evidence suggested the pivotal role of transcriptional mechanism, including but not limited to miRNA, lncRNA, exosome, and so forth, for the cerebral blood flow autoregulation. In the present review, we sought to summarize the hemodynamic changes and underline neural vascular mechanism for cerebral blood flow autoregulation in stroke-prone state and after hemorrhagic stroke and hopefully provide more systematic and innovative research interests for the pathophysiology and therapeutic strategies of hemorrhagic stroke.

\section{Introduction}

Human brain receives almost $20 \%$ of body's oxygen and glucose of cardiac output. Both oxygen and glucose are delivered to the central nervous system by cerebral blood flow (CBF) and then transported across blood-brain barrier for the brain consumption. Therefore, brain functions depend on the proper $\mathrm{CBF}$ due to the normal autoregulation of healthy blood vessels and cardiovascular system. If CBF stops, brain functions will shut down in seconds and neurons will be irreversibly damaged in minutes.

CBF is maintained by a coordinated action of interconnected blood vessels, which in the human brain form a 400mile long vascular network. Within this network, cerebral arteries, arterioles, and capillaries supply the brain with oxygen, energy metabolites, and nutrients. The cerebral venous return removes carbon dioxide and metabolic waste products from the brain and into the systemic circulation for clearance. During the initial stages of hemorrhagic stroke, including intracerebral hemorrhage (ICH) and subarachnoid hemorrhage (SAH), the reflex mechanisms are activated to protect cerebral perfusion, but secondary dysfunction of cerebral flow autoregulation will eventually reduce global $\mathrm{CBF}$ and the delivery of metabolic substrates, leading to generalized cerebral ischemia, hypoxia, and ultimately, neuronal cell death.

$\mathrm{CBF}$ is controlled by various regulatory mechanisms, including prevailing arterial pressure, intracranial pressure, arterial blood gases, neural activity, and metabolic demand. Evoked by the concept of vascular neural network, the unveiled neural vascular mechanism gains more and more attentions. This mechanism ensures a rapid increase in the rate of $\mathrm{CBF}$ to activated brain structures. Under physiological conditions, the capacity of increased $\mathrm{CBF}$ and oxygen 
delivery exceeds metabolic demand and oxygen consumption by activated brain sites, thus providing a large gradient for oxygen diffusion to brain cells furthest from capillaries. And different cell types, such as astrocyte, neuron, pericyte, endothelium, and so forth, are formed as a communicate network to regulate with each other as well as the cerebral blood flow. However, the signaling molecules responsible for this communication between these new players and blood vessels are yet to be definitively confirmed. Recent evidence suggested the pivotal role of transcriptional mechanism, including but not limited to miRNA, lncRNA, exosome, and so forth, for the CBF autoregulation. In the present review, we sought to summarize the hemodynamic changes and underline neural vascular mechanism for CBF autoregulation (Figure 1) in stroke-prone state and after hemorrhagic stroke and hopefully provide more systematic and innovative research interests for the pathophysiology and therapeutic strategies of hemorrhagic stroke.

\section{Hemodynamic Changes in Stroke-Prone State and Hemorrhagic Stroke State}

2.1. Intracerebral Hemorrhage. ICH is the second most common cause of stroke, which initiates with brain parenchyma bleeding and hematoma growth, despite of the direct incentives [1]. Because ICH was thought to be an arterial hemorrhagic brain injury, there is little attention to the role of cerebral vein or venule in ICH pathophysiology $[1,2]$. However, in the acute phase of $\mathrm{ICH}$, a rapid increase of intracranial pressure due to hematoma formation could cause failure of autoregulation and reduce cerebral perfusion pressure [3]. That is why the guidelines suggest controlled lowering blood pressure treatment instead of aggressive lowering blood pressure, which intends to maintain the cerebral blood flow [4]. Moreover, recent studies found that there are new ischemic lesions coexisting with acute ICH [5-9], suggesting possible involvement of small vessel pathogenesis $[5,6]$.

The main secondary brain injury after ICH is thought to be three intertwined degenerative cascades adjacent to hematoma [10], including inflammation [11], red cell lysis and iron deposition [1, 12], and thrombin production [1, 12]. Moreover, besides the ischemic lesions near hematoma, there also are some remote ischemic lesions been found [3]. Similar to ischemic brain injury we reviewed above, all of these pathophysiological factors could directly and indirectly cause cerebral venule endothelial dysfunction, microthrombus, and eventually outflow reduction. Combined with other pathophysiological mechanisms, such as oxidative stress, apoptosis, and others, these factors could also lead to blood-brain barrier disruption, brain edema, and hydrocephalus, which makes further increased intracranial pressure and a vicious cycle [10]. On the other hand, most of intracranial hemorrhage occurs in hypertension patient, and the hypertensive vasculopathy, including arteries/arterioles and veins/venules, could cause "stroke-prone state" to lower the threshold of ischemic [3] and outflow dysfunction [13].

2.2. Subarachnoid Hemorrhage. Subarachnoid hemorrhage is a special subtype of intracranial hemorrhage, which caused by bleeding into subarachnoid hemorrhage. For a long time, cerebral vasospasm is the classic cause of delayed neurological deterioration after aneurysmal subarachnoid hemorrhage, leading to cerebral ischemia and infarction and thus to poor outcome and occasionally death [14]. However, recent clinical trials have demonstrated marked prevention of vasospasm with the endothelin receptor antagonist clazosentan, yet patient outcome was not improved $[15,16]$. These disappointing results reminded researchers switching interests into early brain injury $[17,18]$, but this concept is merely limited in neurons and overlooks the functions of other cell types. Fortunately, recent evolving concepts, such as neurovascular unit [19], vascular neural network [20], and then vasculo-neuronal-glia triad model [21], noticed the contributions of cerebral microcirculation. However, they all keep cerebral veins and venules at an arm's length.

Rethinking of the failed clazosentan clinical trials, there might be a missing factor that, compare to arteries, endothelin only has less potent as a constrictor in cerebral veins [22], which means powerful endothelin receptor antagonist clazonsentan may not alleviate the "vasospasm" in cerebral venous system after subarachnoid hemorrhage. Moreover, clazosentan did not prevent the formation of microthrombi [23]. Recent studies found that there is also vasospasm in deep cerebral veins after subarachnoid hemorrhage [24], and the diameter significantly decreased 1 day and peaked at 5-7 days after subarachnoid hemorrhage [25]. In the meantime, whether there has diameter reducing in cerebral venules after SAH is still controversial [26-29]. In addition, SAH elicited time- and size-dependent increases in rolling and adherent platelets and leukocytes in cerebral venules [30], which lead to microthrombus and microvascular stasis $[29,31]$. Similar to other brain injuries, subarachnoid hemorrhage can also cause brain edema [21, 32, 33], hydrocephalus $[34,35]$, and then cerebral hypoperfusion [36] just like we reviewed above.

In another way, cerebral venous thrombosis [37-40] or stenosis [41] is also an uncommon etiology of subarachnoid hemorrhage, mostly perimesencephalic subarachnoid hemorrhage [42-44]. Potential cause may be elevated intracranial venous pressure or mechanical swelling of the intracranial venous system, leading to variant of cerebral venous drainage [45-49], arteriovenous malformation [50], and eventually veins or venule breakdown $[36,38,51]$.

2.3. Hypertension. Hypertension is one of the most important risk factors of brain injuries. Sustained high blood pressure could cause smooth muscle cell hypertrophy and then vessel remodeling [52], eventually leading to vessel lumen stenosis and decreased venous distensibility $[53,54]$. In the meantime, hypertension could increase the collagen biosynthesis and deposition in perivascular spaces [55], which could have similar effect to the perivenous cuffs in MS patients [56]. However, the major vascular complication under hypertension condition is endothelial dysfunction [57], which will lead to BBB disruption [58-61] and impairment of vascular tone modulation [57]. In addition, hypertension could also cause adherent leukocytes and platelets in cerebral venules [62]. All these pathophysiological effects could increase 


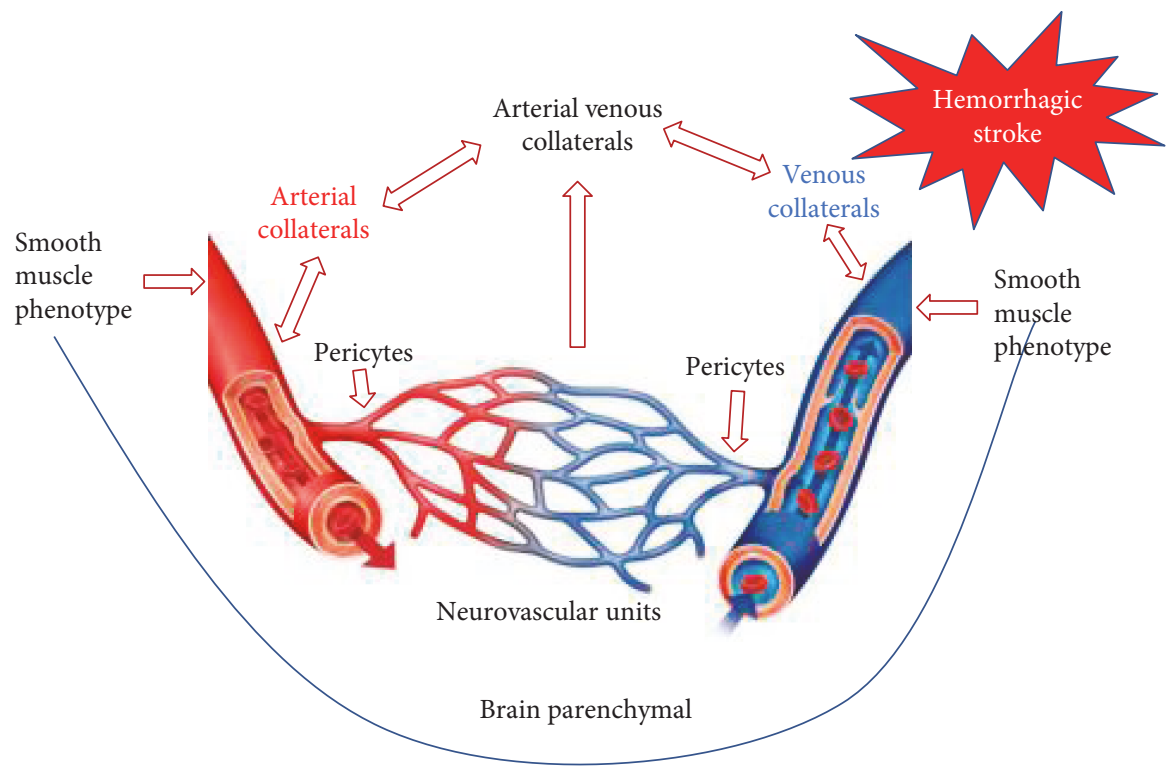

FiguRE 1: Neural vascular mechanisms for the cerebral blood flow autoregulation in the present review.

cerebral venous pressure, impair cerebral venous outflow [63-65], and eventually rCBF reduction [66].

2.4. Diabetes. Diabetes is another major risk factor of stroke. Diabetes develops because of inadequate pancreas islet $\beta$-cell and adipose-tissue responses to chronic fuel excess, which results in nutrition excess, insulin resistance, and metabolic stress [67]. Among these, metabolic stress leads to endothelial dysfunction, including cerebral venous system, which is considered to be the initial process in vascular manifestations of diabetes $[68,69]$. Following vascular related alterations involves platelet adhesiveness and coagulation cascade, vasoconstriction, and inflammation $[69,70]$. Similar to other brain injuries, these pathophysiological changes ultimately lead to cerebral venous thrombus $[71,72]$, venous hyperaemia, and brain edema [73].

\section{Neurovascular Networks as Future Therapeutic Targets}

3.1. Pericytes as a Potential Interventional Target. Pericytes cover venules of superficial cerebral veins in the central nervous system as well as arterioles, which determine the contraction and dilation of these vessels. Recent evidence has suggested that pericytes secrete matrix metalloproteinase- 9 to degrade the endothelial matrix and blood-brain barrier around their somatic bodies. In addition to mechanic stress caused by hyperperfusion after recanalization [74], pericytes may have a fundamental role in the disruption of the bloodbrain barrier in poststroke venules but not arterioles and capillaries. This detrimental function may have been induced by cyclophilin A and its downstream signaling pathways.

However, pericytes have multipotential functions that could underlie blood-brain barrier development and repair. First, pericytes can form intercellular tight junctions in the blood-brain barrier [75]. Additionally, pericytes also contribute to the formation of the basal lamina by synthesizing type
IV collagen, glycosaminoglycans, and laminin (Allt and Lawrenson, 2001). Large efforts have been undertaken to induce angiogenesis and protect the blood-brain barrier [76-79], but it is still far from clinical application. Recently, we successfully stimulated tight junction and adherens junction proteins by activating Frizzled-4 receptor, a canonical Wnt signaling receptor that is also expressed on pericytes [80], suggesting that pericytes may be a promising target to maintain blood-brain barrier integrity and functions during subarachnoid hemorrhage treatment [21].

Furthermore, previous evidence suggests that the occurrence of global ischemia after subarachnoid hemorrhage significantly constricts pericytes and reduces blood flow in the microcirculation. However, in contrast to intuition, dilated pericytes may not reverse blood flow, which we called a "no-reflow phenomenon" [81, 82]. Second, during subarachnoid hemorrhage and other brain injury pathophysiologies, pericyte contraction, usually together with pericyteprogrammed cell death, caused a reduced capillary density and maintained an inactive microcirculation [27, 83, 84]. Our recent studies indicated that pericytes are induced to contract in response to hemoglobin and nitric oxide/cGMP pathway, forming pearl string-like contractions in microvessels to deteriorate the microcirculation [85].

In addition, pericytes could modulate the proliferation, migration, and differentiation of endothelial cells; pericytes cocultured with endothelial cells and astrocytes could establish a stable capillary-like structure [86, 87]. In their efforts to orchestrate initiation, sprout connection, and termination in angiogenesis, pericytes secrete vascular endothelial growth factor and interleukin- 6 to facilitate endothelial cell maturation and microvessel sprouting, contributing a pivotal role in the initial stage of angiogenesis [88]. Transforming growth factor- $\beta$ binds to its receptor on endothelial cells and pericytes to self-regulate and induce perivascular mesenchymal cell differentiation into pericytes and smooth muscle cells [89]. Moreover, the platelet-derived growth factor (PDGF) 
pathway is the crucial factor for sprouting capillary recruitment of pericytes. Angiopoietin-1 from pericytes binds to Tie- 2 on the endothelial cell to enhance pericyte surrounding of the new blood spout, increasing the vessel stability [90].

Due to their specific spatial distribution along microvessels and their broad cellular properties, pericytes could be an ideal target for the development of novel preventive and therapeutic strategies by modulating and controlling the neural vascular network, consequently improving neuroprotection [91]. For example, targeting pericytes during the development of microvascular dysfunction and elucidating the molecular pathways involved in the regulation of pericyte activities for attenuating chronic rejection intervention have been demonstrated [92]. A recent review also targeted pericytes as clinical endpoints and therapeutic interventions in diabetic retinopathy [93]. Interestingly, maintaining high levels of estrogen E2 are critical for the control of PDGFmediated crosstalk between endothelial cells and pericytes, which governs the microvessel stability and is essential for preserving intracranial homeostasis, consequently reducing the risk of intracranial hemorrhage and decreasing the incidence of stroke and cerebral aneurysm [94]. Future studies should further determine the role of pericytes before and after hemorrhage to illustrate the mechanism underlying the occurrence and development of this critical disorder. Additional drugs and trials targeting pericytes and their effectiveness are also required to develop new strategies for the prevention and treatment of hemorrhagic stroke.

3.2. Smooth Muscle Phenotype for Autoregulation. In addition to pericytes, smooth muscle cells also contribute to regulation of the cerebral blood supply with much greater strength. In fact, some researchers consider the smooth muscle cells as the dominator for microvessel autoregulation. In 1993, Contard et al. demonstrated that smooth muscle phenotypes in stroke-prone spontaneously hypertensive rats had no effect on blood pressure or associations with thickness [95]. Most importantly, the changes in the smooth muscle cell phenotype may be beneficial for ischemic tissue lesions in the heart [95]. After traumatic brain injury, mechanical stress can also induce subarachnoid hemorrhage, similar to vasospasm in response to smooth muscle cell hypercontractility and phenotype switching for prolonged vessel remodeling and lumen occlusion. Our recent experiments also propose a potential role for the maintenance of the cerebral smooth muscle phenotype in early brain injury after subarachnoid hemorrhage [96].

Regarding its internal mechanism, the smooth muscle phenotype was mainly regulated by platelet-derived growth factor-BB (PDGF-BB), which has been reported to stimulate smooth muscle cell differentiation, proliferation, and phenotypic transformation [97]. Additionally, PDGF-BB induces the differentiation of the bone marrow endothelial progenitor cell-derived cell line TR-BME2 into mural cells/pericytes and alters the smooth muscle cell phenotype [98]. Other studies have suggested that the ACTA2 gene, calcium signals, cadherin $6 \mathrm{~B}$, and integrin receptor may also participate in this pathophysiological process [96, 99-101]. Due to limited evidence in this field, especially in the central nervous system, additional efforts are still needed to elucidate the pivotal role of the smooth muscle phenotype in autoregulation after stroke and other central nervous system disorders.

3.3. Collaterals for Recirculation. Due to the great contributions of the collateral circulation to stroke outcomes, we wondered how to manipulate this important and neglected factor in previous stroke pathophysiologies and therapies. Current strategies include the following. (1) Statins may open collaterals after stroke, preserve penumbra, and expand the time window of thrombolysis $[102,103]$. Ovbiagele et al. evaluated the relationship between prestroke statin use and pretreatment angiographic collateral grade among patients with acute ischemic stroke, and they found that the statintreated group had significantly higher collateral scores than the nonstatin users, suggesting an association between statin use and improved collateralization during acute stroke [104]. (2) Intracellular chloride channel 4 is a determinant of native collateral formation in the brain [105]. Chalothorn et al. observed reduced collateral formation in mice that were deficient in chloride intracellular channel 4 , which displayed greater ischemia and worse perfusion [106] and recovery [106]. (3) Vascular endothelial growth factor (VEGF) may be specific for collateral development. Harrigan et al. treated MCAO rats with chronic intraventricular infusions of VEGF, which increased the vascular density in a dose-dependent manner and minimized the associated brain edema after ischemic stroke $[107,108]$. (4) Pioglitazone reduces the nonflow phenomenon in microvessels. Shimazu et al. found that the peroxisome proliferator-activated receptor-gamma $(\mathrm{PPAR} \gamma)$ agonist reduces the infarction size in transient but not permanent MCAO, suggesting that the role of PPAR $\gamma$ is specific to events that occur during reperfusion, possibly the collateral circulation [109]. During the postischemic, reperfusion phase, pioglitazone, a synthetic agonist for $\operatorname{PPAR} \gamma$, also improves recovery from ischemic stroke [110]. Nevertheless, due to the outlook for collateral circulation, especially the venous collaterals, in translational stroke research over the past decades, limited strategies have been discovered and developed. In future studies, an improved understanding of collateral hemostasis after stroke and of precision therapeutic therapies is highly encouraged. And the pathophysiological therapeutic time window, depending on the collateral circulation of the patient, might replace the current suggested time window for the endovascular treatment after stroke.

\section{Transcriptional Signals for the Autoregulation}

4.1. Classical Molecule Signals. As we summarized above, cerebral autoregulation, an inherent ability to maintain a relatively steady-state CBF despite fluctuation in arterial blood pressure, is attributed to an intrinsic ability of smooth muscle cells and pericytes to constrict or relax to minimize variation in CBF. The signaling event underlying myogenic response consists of an activation of stretch-activated $\mathrm{Ca}^{2+}$ channels by an increase in intravascular pressure [111]. This results in an elevation in intracellular $\mathrm{Ca}^{2+}$ and subsequent 
stimulation of phospholipase A2, leading to the release of arachidonic acid from membrane phospholipids. Arachidonic acid metabolites, 20-HETEs, inhibit $\mathrm{Ca}^{2+}$-dependent $\mathrm{K}$ channels resulting in depolarization of smooth muscles and vasoconstriction. Functional hyperemia implies an increase in CBF induced by neural activity to meet the local metabolic demand. This is a well-coordinated event involving neurons, astrocytes, and vascular cells.

It is widely assumed that calcium-dependent release of vasoactive substances by astrocytes results in arteriole dilation and the increased blood flow which accompanies neuronal activity. Howarth [112] summarized the evidence which has convincingly demonstrated that astrocytes are able to modify the diameter of cerebral arterioles. Howarth discussed the prevalence, presence, and timing of stimulusinduced astrocyte calcium transients and described the evidence for and against the role of calcium-dependent formation and release of vasoactive substances by astrocytes.

4.2. Transcriptional Modulators. Nuclear factor-kappa B (NF-kappaB) is a multisubunit transcription factor that when activated induces the expression of genes encoding acute-phase proteins, cell adhesion molecules, cell surface receptors, and cytokines. Stephenson et al. [113] demonstrate that transient focal cerebral ischemia results in activation of NF-kappaB in neurons and supports previous observations that neuroprotective antioxidants may inhibit neuronal death by preventing the activation of NF-kappaB. Samraj et al. [114], using system biology tools and experimental SAH models, have identified signal transducer and activator of transcription 3 (STAT3) transcription factor as a possible major regulatory molecule in late cerebral ischemia after subarachnoid hemorrhage.

4.3. Genomic Targets for Autoregulation. miRNAs play important regulatory roles in a variety of cellular functions as well as in several diseases, including stroke. Jeyaseelan et al. [115] showed miR-103 and rno-miR-107 related to transient focal ischemia by middle cerebral artery occlusion. Wang et al. [116] concluded that miR-29b could potentially predict stroke outcomes as a novel circulating biomarker and miR-29b overexpression reduced BBB disruption after ischemic stroke. MicroRNA-210 (miR-210), a master and pleiotropic hypoxia-microRNA, plays multiple roles in brain ischemia. Zeng et al. [117] valuate the correlation of blood miR-210 with clinical findings in acute ischemic stroke and found blood miR-210 is a novel sensitive biomarker for clinical diagnosis and prognosis in acute cerebral ischemia. Yin et al. [118] suggest that miR-497 promotes ischemic neuronal death by negatively regulating antiapoptotic proteins, bcl-2 and bcl-w. We raise the possibility that this pathway may contribute to the pathogenesis of the ischemic brain injury in stroke. Gan et al. [119] demonstrated that hemostatic mechanisms are affected by ischemic stroke and concluded that circulating microRNA-145 has potential as a biomarker for ischemic stroke.

4.4. Big Data Analysis for the CBF Autoregulation. Many data mining methods are used in the field of $\mathrm{CBF}$ regulation, such as nonlinear analysis [1], which is often used to analyze the relationship between CBF regulation and other factors. For example, Saleem et al. [120] determine the consistency of dynamic cerebral autoregulation by characterizing the pressure-flow relationships. Mitsis et al. [121] build a nonlinear model of the dynamic effects of arterial pressure and blood gas variations on cerebral blood flow in healthy humans. Tan [122] defined the characteristic relationship between arterial pressure and cerebral flow. Mitsis et al. [123] assessed by examining the dynamic relationship between spontaneous fluctuations of cerebral blood flow and arterial blood pressure under various levels of lower body negative pressure in healthy humans. Other data mining methods are used in the field too. Chiu et al. [124] use time domain cross-correlation analysis of prefiltered mean arterial blood pressure and mean cerebral blood flow velocity which were applied to assess the cerebral autoregulation. Liau et al. [125] use time domain cross-correlation function which was applied to evaluate the relationship between blood pressure and cerebral blood flow velocity signals acquiring from healthy subjects and stroke patients both in supine and head-up tilt positions to evaluate the effect of posture change. Chacón et al. [126] posit a nonlinear model of the CBF autoregulation system through the evaluation of various types of neural networks [127] that have been used in the field of system identification. Chiu et al. [128] use support vector machine to [129] build a classification of dynamic cerebral autoregulation in diabetics with autonomic neuropathy. Liau et al. [130] used chaotic analysis [131] in diabetic autonomic neuropathy and assessed dynamic cerebral autoregulation and suggested that impaired autoregulation would be more chaotic and less predictable.

Although many data mining techniques have been applied to the field, but in some researches, the amount of data is small, which has a great impact on the accuracy of the algorithm or model. At present, big data [132] are very broadly used, and we can use big data technology to improve this problem. There are a lot of big data applications on the field of stroke therapy [133-135], but there is little reference to big data in the cerebral blood flow autoregulation research. There are numerous imaging techniques such as SPECT, CT, MRI, and PET used in the cerebral blood flow research field [136], and as we know, the amount of image data is far more than the other data, and we can use big data technology and its 3V (velocity, volumes, and variety) [132] feature to improve the algorithm or model. Big data can also be used for genetic data analysis to find genomic targets for autoregulation. Also, the computer industry has transitioned into multicore and many-core parallel systems [137] and GPU programming like CUDA [138] are wildly used in speeding up algorithms. We can also employ high performance computing and related data mining algorithm [139-145] to speed up the algorithms of the cerebral blood flow research.

\section{Hemodynamic Changes for Therapeutic Strategies of Hemorrhagic Stroke}

The central spirit of summarizing CBF autoregulation mechanism is to help reperfusing the ischemic brain region after 
hemorrhagic stroke. Compared to the progressive stage of shock, when the compensatory mechanisms begin to fail, blood remains in the capillaries, leading to tissue anoxia, and there are somehow similarity with cerebral congestion under cerebral venous dysfunction. We might get benefit to diagnose the prevalence of cerebral venous dysfunction by monitoring $\mathrm{rCBF}[146,147]$ due to autoregulation failure and blood congestion, $\mathrm{SjvO}_{2}[148,149]$ due to significantly reduced brain energy consumption, and lactate $[150,151]$ of internal jugular vein due to sustained anaerobic metabolism in related brain regions. Moreover, carefully monitoring cerebral venous drainage could be applied to prognostic evaluation after brain injury [152].

Current reperfusion treatment barely involves cerebral venous system, including surgical interventions such as aneurysm clipping or coiling [153], which can be used to prevent rebleeding after subarachnoid hemorrhage. Mechanical clot-retrieving devices [154] or chemical agents such as rtPA [155] are used to reopen occluded arteries. However, these treatments might not effectively restore the blood flow in capillary and downstream venous system. Existing data support the use of systemic anticoagulation as an initial therapy in all patients [156], even in the presence of hemorrhage. Interestingly, Simard et al. recently demonstrated that lowdose intravenous heparin infusion after surgery in patients with aneurysmal subarachnoid hemorrhage is safe and beneficial [157]. Furthermore, while controversial, surgical interventions are being used to reverse the possible pathogenesis chronic cerebrospinal venous insufficiency [158]. And improved decompressive craniotomy could alleviate intervention toward cerebral venous system and less brain damage $[36,159]$. In sum, carefully monitoring and treating the cerebral venous dysfunction are critical, therefore, to effectively restore optimal cerebrovascular function.

\section{Perspective and Conclusion}

During the initial stages of hemorrhagic stroke, including intracerebral hemorrhage and subarachnoid hemorrhage, the reflex mechanisms are activated to protect cerebral perfusion, but secondary dysfunction of cerebral flow autoregulation will eventually reduce global cerebral blood flow and the delivery of metabolic substrates, leading to generalized cerebral ischemia, hypoxia, and ultimately, neuronal cell death. Evoked by the concept of vascular neural network, the unveiled neural vascular mechanism gains more and more attentions. Different cell types and molecular and transcriptional modulators may be involved in the neural vascular mechanism for $\mathrm{CBF}$ autoregulation. However, current understandings could not explain all the clinical phenomenon and strategies for autoregulation after hemorrhagic stroke.

Recently, application of the cerebral venous dysfunction for hemorrhagic stroke pathophysiology presents an opportunity to identify how cerebral venous system is involved in the prone vulnerability of brain injury and the control of reperfusion. This strategy expands the vascular neural network by improved understanding of cerebral venous system playing a key role in the mechanism of brain injury.
However, more research is needed to figure out the time course of cerebral venous changes after hemorrhagic stroke and their implications for the CBF autoregulation. And studies are also needed to investigate the interactions between different kinds of cell types in the CBF autoregulation before and after hemorrhagic stroke. Communications among venous endothelial cells, pericytes, astrocytes, smooth muscle cells, and perivascular neurons should be studied systematically to elucidate how and when these happen. More precised animal models and detective method toward CBF autoregulation are also needed. Ultimately, these efforts should facilitate the development of therapeutic strategies, no matter surgeries or pharmacological agents target the sewerage system of the brain and all kinds of plumbers that serve to build, maintain, and regulate it.

\section{Conflicts of Interest}

The authors declare no conflict of interests.

\section{Acknowledgments}

This study was funded by the National Natural Science Foundation of China (no. 81501002 to Yujie Chen and no. 81220108009 to Hua Feng), the Major Innovation Project of Southwest Hospital (no. SWH2016ZDCX1011 to Hua Feng), the National Basic Research Program of China (973 Program, no. 2014CB541600 to Hua Feng), and the Basic Science and Advanced Technology Research Project of Chongqing (no. cstc2016jcyjA1730 to Yujie Chen).

\section{References}

[1] G. Xi, R. F. Keep, and J. T. Hoff, "Mechanisms of brain injury after intracerebral haemorrhage," Lancet Neurology, vol. 5, no. 1, pp. 53-63, 2006.

[2] M. N. Diringer, "Intracerebral hemorrhage: pathophysiology and management," Critical Care Medicine, vol. 21, no. 10, pp. 1591-1603, 1993.

[3] S. Prabhakaran and A. M. Naidech, "Ischemic brain injury after intracerebral hemorrhage: a critical review," Stroke, vol. 43, no. 8, pp. 2258-2263, 2012.

[4] L. B. Morgenstern, J. C. Hemphill, C. Anderson et al., "Guidelines for the management of spontaneous intracerebral hemorrhage: a guideline for healthcare professionals from the American Heart Association/American Stroke Association," Stroke, vol. 41, no. 9, pp. 2108-2129, 2010.

[5] D. W. Kang, M. K. Han, H. J. Kim et al., "New ischemic lesions coexisting with acute intracerebral hemorrhage," Neurology, vol. 79, no. 9, pp. 848-855, 2012.

[6] S. M. Gregoire, A. Charidimou, N. Gadapa et al., "Acute ischaemic brain lesions in intracerebral haemorrhage: multicentre cross-sectional magnetic resonance imaging study," Brain, vol. 134, Part 8, pp. 2376-2386, 2011.

[7] R. S. Menon, R. E. Burgess, J. J. Wing et al., "Predictors of highly prevalent brain ischemia in intracerebral hemorrhage," Annals of Neurology, vol. 71, no. 2, pp. 199-205, 2012.

[8] S. Prabhakaran, R. Gupta, B. Ouyang et al., "Acute brain infarcts after spontaneous intracerebral hemorrhage: a 
diffusion-weighted imaging study," Stroke, vol. 41, no. 1, pp. 89-94, 2010.

[9] W. T. Kimberly, A. Gilson, N. S. Rost et al., "Silent ischemic infarcts are associated with hemorrhage burden in cerebral amyloid angiopathy," Neurology, vol. 72, no. 14, pp. 12301235, 2009.

[10] W. C. Ziai, "Hematology and inflammatory signaling of intracerebral hemorrhage," Stroke, vol. 44, no. 6, Supplement 1, pp. S74-S78, 2013.

[11] J. Wang, "Preclinical and clinical research on inflammation after intracerebral hemorrhage," Progress in Neurobiology, vol. 92, no. 4, pp. 463-477, 2010.

[12] Y. Hua, R. F. Keep, J. T. Hoff, and G. Xi, "Brain injury after intracerebral hemorrhage: the role of thrombin and iron," Stroke, vol. 38, no. 2, pp. 759-762, 2007.

[13] G. A. Bateman, "Association between arterial inflow and venous outflow in idiopathic and secondary intracranial hypertension," Journal of Clinical Neuroscience, vol. 13, no. 5, pp. 550-556, 2006, discussion 557.

[14] R. L. Macdonald, R. M. Pluta, and J. H. Zhang, "Cerebral vasospasm after subarachnoid hemorrhage: the emerging revolution," Nature Clinical Practice Neurology, vol. 3, no. 5, pp. 256-263, 2007.

[15] R. L. Macdonald, N. F. Kassell, S. Mayer et al., "Clazosentan to overcome neurological ischemia and infarction occurring after subarachnoid hemorrhage (CONSCIOUS-1): randomized, double-blind, placebo-controlled phase 2 dose-finding trial," Stroke, vol. 39, no. 11, pp. 3015-3021, 2008.

[16] R. L. Macdonald, R. T. Higashida, E. Keller et al., "Clazosentan, an endothelin receptor antagonist, in patients with aneurysmal subarachnoid haemorrhage undergoing surgical clipping: a randomised, double-blind, placebo-controlled phase 3 trial (CONSCIOUS-2)," Lancet Neurology, vol. 10, no. 7, pp. 618-625, 2011.

[17] J. Cahill and J. H. Zhang, "Subarachnoid hemorrhage: is it time for a new direction?," Stroke, vol. 40, no. 3, Supplement 1, pp. S86-S87, 2009.

[18] F. A. Sehba, R. M. Pluta, and J. H. Zhang, "Metamorphosis of subarachnoid hemorrhage research: from delayed vasospasm to early brain injury," Molecular Neurobiology, vol. 43, no. 1, pp. 27-40, 2011.

[19] E. H. Lo and G. A. Rosenberg, "The neurovascular unit in health and disease: introduction," Stroke, vol. 40, no. 3, Supplement 1, pp. S2-S3, 2009.

[20] J. H. Zhang, J. Badaut, J. Tang, A. Obenaus, R. Hartman, and W. J. Pearce, "The vascular neural network-a new paradigm in stroke pathophysiology," Nature Reviews Neurology, vol. 8, no. 12, pp. 711-716, 2012.

[21] S. Chen, H. Feng, P. Sherchan et al., "Controversies and evolving new mechanisms in subarachnoid hemorrhage," Progress in Neurobiology, vol. 115, pp. 64-91, 2014.

[22] J. E. Hardebo, J. Kåhrström, C. Owman, and L. G. Salford, "Endothelin is a potent constrictor of human intracranial arteries and veins," Blood Vessels, vol. 26, no. 5, pp. 249253, 1989.

[23] G. Chen, A. Tariq, J. Ai et al., "Different effects of clazosentan on consequences of subarachnoid hemorrhage in rats," Brain Research, vol. 1392, pp. 132-139, 2011.

[24] Z. Dai, X. Deng, Z. Zhang et al., "MRI study of deep cerebral veins after subarachniod hemorrhage in rabbits,"
Chinese Journal of Clinical Anatomy, vol. 30, no. 2, pp. 176-180, 2012.

[25] Z. Zhang, X. Deng, Z. Dai et al., "MRI image of the internal cerebral vein and basilar artery of rabbit following subarachnoid hemorrhage," Chinese Journal of Clinical Anatomy, vol. 35, no. 2, pp. 137-140, 2012.

[26] B. L. Sun, C. B. Zheng, M. F. Yang, H. Yuan, S. M. Zhang, and L. X. Wang, "Dynamic alterations of cerebral pial microcirculation during experimental subarachnoid hemorrhage," Cellular and Molecular Neurobiology, vol. 29, no. 2, pp. 235-241, 2009.

[27] E. Uhl, J. Lehmberg, H. J. Steiger, and K. Messmer, "Intraoperative detection of early microvasospasm in patients with subarachnoid hemorrhage by using orthogonal polarization spectral imaging," Neurosurgery, vol. 52, no. 6, pp. 13071315, 2003, disacussion 1315-7.

[28] E. Perkins, H. Kimura, A. D. Parent, and J. H. Zhang, "Evaluation of the microvasculature and cerebral ischemia after experimental subarachnoid hemorrhage in dogs," Journal of Neurosurgery, vol. 97, no. 4, pp. 896-904, 2002.

[29] B. Friedrich, F. Müller, S. Feiler, K. Schöller, and N. Plesnila, "Experimental subarachnoid hemorrhage causes early and long-lasting microarterial constriction and microthrombosis: an in-vivo microscopy study," Journal of Cerebral Blood Flow and Metabolism, vol. 32, no. 3, pp. 447-455, 2012.

[30] M. Ishikawa, G. Kusaka, N. Yamaguchi et al., "Platelet and leukocyte adhesion in the microvasculature at the cerebral surface immediately after subarachnoid hemorrhage," Neurosurgery, vol. 64, no. 3, pp. 546-553, 2009, discussion 553-4.

[31] L. K. Bittencourt, F. Palma-Filho, R. C. Domingues, and E. L. Gasparetto, "Subarachnoid hemorrhage in isolated cortical vein thrombosis: are presentation of an unusual condition," Arquivos de Neuro-Psiquiatria, vol. 67, no. 4, pp. 1106-1108, 2009.

[32] F. A. Sehba, J. Hou, R. M. Pluta, and J. H. Zhang, "The importance of early brain injury after subarachnoid hemorrhage," Progress in Neurobiology, vol. 97, no. 1, pp. 14-37, 2012.

[33] J. Cahill, J. W. Calvert, and J. H. Zhang, "Mechanisms of early brain injury after subarachnoid hemorrhage," Journal of Cerebral Blood Flow and Metabolism, vol. 26, no. 11, pp. 1341-1353, 2006.

[34] A. H. Shah and R. J. Komotar, "Pathophysiology of acute hydrocephalus following subarachnoid hemorrhage," World Neurosurgery, vol. 80, no. 3-4, pp. 304-306, 2013.

[35] S. Okubo, J. Strahle, R. F. Keep, Y. Hua, and G. Xi, "Subarachnoid hemorrhage-induced hydrocephalus in rats," Stroke, vol. 44, no. 2, pp. 547-550, 2013.

[36] A. Csókay, G. Pataki, L. Nagy, and K. Belán, "Vascular tunnel construction in the treatment of severe brain swelling caused by trauma and SAH. (evidence based on intra-operative blood flow measure)," Neurological Research, vol. 24, no. 2, pp. 157-160, 2002.

[37] H. El Otmani, F. Moutaouakil, H. Fadel, and I. Slassi, "Subarachnoid hemorrhage induced by cerebral venous thrombosis," Journal des Maladies Vasculaires, vol. 37, no. 6, pp. 323-325, 2012.

[38] Y. Kato, H. Takeda, D. Furuya et al., "Subarachnoid hemorrhage as the initial presentation of cerebral venous thrombosis," Internal Medicine, vol. 49, no. 5, pp. 467-470, 2010.

[39] Y. Benabu, L. Mark, S. Daniel, and R. Glikstein, "Cerebral venous thrombosis presenting with subarachnoid 
hemorrhage: case report and review," The American Journal of Emergency Medicine, vol. 27, no. 1, pp. 96-106, 2009.

[40] R. Shukla, P. Vinod, S. Prakash, R. V. Phadke, and R. K. Gupta, "Subarachnoid haemorrhage as a presentation of cerebral venous sinus thrombosis," The Journal of the Association of Physicians of India, vol. 54, pp. 42-44, 2006.

[41] A. Shad, T. J. Rourke, A. Hamidian Jahromi, and A. L. Green, "Straight sinus stenosis as a proposed cause of perimesencephalic non-aneurysmal haemorrhage," Journal of Clinical Neuroscience, vol. 15, no. 7, pp. 839-841, 2008.

[42] J. Lee, E. M. Koh, C. S. Chung et al., "Underlying venous pathology causing perimesencephalic subarachnoid hemorrhage," The Canadian Journal of Neurological Sciences, vol. 36, no. 5, pp. 638-642, 2009.

[43] M. S. Sangra, E. Teasdale, M. A. Siddiqui, and K. W. Lindsay, "Perimesencephalic nonaneurysmal subarachnoid hemorrhage caused by jugular venous occlusion: case report," Neurosurgery, vol. 63, no. 6, pp. E1202-E1203, 2008, discussion E1203.

[44] M. S. Mathews, D. Brown, and M. Brant-Zawadzki, "Perimesencephalic nonaneurysmal hemorrhage associated with vein of Galen stenosis," Neurology, vol. 70, 24 Part 2, pp. 24102411, 2008.

[45] J. N. Song, H. Chen, M. Zhang, Y. L. Zhao, and X. D. Ma, "Dynamic change in cerebral microcirculation and focal cerebral metabolism in experimental subarachnoid hemorrhage in rabbits," Metabolic Brain Disease, vol. 28, no. 1, pp. 3343, 2013.

[46] Y. Kawamura, O. Narumi, M. Chin, and S. Yamagata, "Variant deep cerebral venous drainage in idiopathic subarachnoid hemorrhage," Neurologia Medico-Chirurgica (Tokyo), vol. 51, no. 2, pp. 97-100, 2011.

[47] H. Yamakawa, N. Ohe, H. Yano, S. Yoshimura, and T. Iwama, "Venous drainage patterns in perimesencephalic nonaneurysmal subarachnoid hemorrhage," Clinical Neurology and Neurosurgery, vol. 110, no. 6, pp. 587591, 2008.

[48] J. F. Alén, A. Lagares, J. Campollo et al., "Idiopathic subarachnoid hemorrhage and venous drainage: are they related?," Neurosurgery, vol. 63, no. 6, pp. 1106-1111, 2008, discussion 1111-2.

[49] I. C. van der Schaaf, B. K. Velthuis, A. Gouw, and G. J. Rinkel, "Venous drainage in perimesencephalic hemorrhage," Stroke, vol. 35, no. 7, pp. 1614-1618, 2004.

[50] A. Hashiguchi, C. Mimata, H. Ichimura, M. Morioka, and J. Kuratsu, "Venous aneurysm development associated with a dural arteriovenous fistula of the anterior cranial fossa with devastating hemorrhage-case report," Neurologia MedicoChirurgica (Tokyo), vol. 47, no. 2, pp. 70-73, 2007.

[51] T. Matsuyama, K. Okuchi, T. Seki, T. Higuchi, and Y. Murao, "Perimesencephalic nonaneurysmal subarachnoid hemorrhage caused by physical exertion," Neurologia MedicoChirurgica (Tokyo), vol. 46, no. 6, pp. 277-281, 2006, discussion 281-2.

[52] G. Faraco and C. Iadecola, "Hypertension: a harbinger of stroke and dementia," Hypertension, vol. 62, no. 5, pp. 810-817, 2013.

[53] M. A. Fitzpatrick, A. L. Hinderliter, B. M. Egan, and S. Julius, "Decreased venous distensibility and reduced renin responsiveness in hypertension," Hypertension, vol. 8, 6 Part 2, pp. II36-II43, 1986.
[54] N. Ito, A. Takeshita, S. Higuchi, and M. Nakamura, "Venous abnormality in normotensive young men with a family history of hypertension," Hypertension, vol. 8, no. 2, pp. 142-146, 1986.

[55] S. Spector, A. Ooshima, K. Iwatsuki, G. Fuller, G. Cardinale, and S. Udenfriend, "Increased vascular collagen biosynthesis by hypertension and reversal by antihypertensive drugs," Blood Vessels, vol. 15, no. 1-3, pp. 176-182, 1978.

[56] W. R. Brown and C. R. Thore, "Perivascular fibrosis in multiple sclerosis lesions," Brain Pathology, vol. 21, no. 3, p. 355, 2011.

[57] D. D. Heistad and G. L. Baumbach, "Cerebral vascular changes during chronic hypertension: good guys and bad guys," Journal of Hypertension Supplement, vol. 10, no. 7, pp. S71-S75, 1992.

[58] H. Al-Sarraf and L. Philip, "Effect of hypertension on the integrity of blood brain and blood CSF barriers, cerebral blood flow and CSF secretion in the rat," Brain Research, vol. 975, no. 1-2, pp. 179-188, 2003.

[59] W. G. Mayhan, "Role of activation of bradykinin $B_{2}$ receptors in disruption of the blood-brain barrier during acute hypertension," Brain Research, vol. 738, no. 2, pp. 337-341, 1996.

[60] A. H. Werber and M. C. Fitch-Burke, "Pial venous pressure and acute hypertensive disruption of the blood-brain barrier in spontaneous and renal hypertension," Brain Research, vol. 515, no. 1-2, pp. 235-240, 1990.

[61] W. G. Mayhan, F. M. Faraci, J. L. Siems, and D. D. Heistad, "Role of molecular charge in disruption of the blood-brain barrier during acute hypertension," Circulation Research, vol. 64, no. 4, pp. 658-664, 1989.

[62] S. F. Rodrigues, S. A. Vital, and D. N. Granger, "Mild hypercholesterolemia blunts the proinflammatory and prothrombotic effects of hypertension on the cerebral microcirculation," Journal of Cerebral Blood Flow and Metabolism, vol. 33, no. 4, pp. 483-489, 2013.

[63] T. J. Roberts, A. C. Chapman, and M. J. Cipolla, "PPAR- $\gamma$ agonist rosiglitazone reverses increased cerebral venous hydraulic conductivity during hypertension," American Journal of Physiology Heart and Circulatory Physiology, vol. 297, no. 4, pp. H1347-H1353, 2009.

[64] T. M. Ripp, I. A. Astanina, I. N. Vorozhtsova, V. F. Mordovin, and R. S. Karpov, "Function of the brain venous system and a 24-h profile of arterial pressure in hypertensive patients," Terapevticheskil Arkhiv, vol. 77, no. 12, pp. 22-25, 2005.

[65] D. J. Langer, T. M. Lasner, R. W. Hurst, E. S. Flamm, E. L. Zager, and J. T. King Jr, "Hypertension, small size, and deep venous drainage are associated with risk of hemorrhagic presentation of cerebral arteriovenous malformations," Neurosurgery, vol. 42, no. 3, pp. 481-489, 1998.

[66] O. Z. Chi, H. M. Wei, J. Tse, S. L. Klein, and H. R. Weiss, "Cerebral microregional oxygen balance during chronic versus acute hypertension in middle cerebral artery occluded rats," Anesthesia and Analgesia, vol. 82, no. 3, pp. 587-592, 1996.

[67] C. J. Nolan, P. Damm, and M. Prentki, "Type 2 diabetes across generations: from pathophysiology to prevention and management," Lancet, vol. 378, no. 9786, pp. 169-181, 2011.

[68] P. C. Deedwania, "Diabetes is a vascular disease: the role of endothelial dysfunction in pathophysiology of cardiovascular disease in diabetes," Cardiology Clinics, vol. 22, no. 4, pp. 505-509, 2004. 
[69] M. A. Creager, T. F. Lüscher, F. Cosentino, and J. A. Beckman, "Diabetes and vascular disease: pathophysiology, clinical consequences, and medical therapy: part I," Circulation, vol. 108, no. 12, pp. 1527-1532, 2003.

[70] A. Mafrici and R. Proietti, "Atherothrombosis in patients with type 2 diabetes mellitus: an overview of pathophysiology," Giornale Italiano di Cardiologia (Rome), vol. 11, no. 6, pp. 467-477, 2010.

[71] L. S. Usdan, K. W. Choong, and M. E. McDonnell, "Type 2 diabetes mellitus manifesting with a cerebral vein thrombosis and ketoacidosis," Endocrine Practice, vol. 13, no. 6, pp. 687690, 2007.

[72] M. J. Sasiadek, D. Sosnowska-Pacuszko, M. Zielinska, and T. Turek, "Cerebral venous thrombosis as a first presentation of diabetes," Pediatric Neurology, vol. 35, no. 2, pp. 135-138, 2006.

[73] A. P. Carlotti, C. St George-Hyslop, A. M. Guerguerian, D. Bohn, K. S. Kamel, and M. Halperin, "Occult risk factor for the development of cerebral edema in children with diabetic ketoacidosis: possible role for stomach emptying," Pediatric Diabetes, vol. 10, no. 8, pp. 522-533, 2009.

[74] I. Linfante and M. J. Cipolla, "Improving reperfusion therapies in the era of mechanical thrombectomy," Translational Stroke Research, vol. 7, no. 4, pp. 294-302, 2016.

[75] F. Shimizu, Y. Sano, T. Maeda et al., "Peripheral nerve pericytes originating from the blood-nerve barrier expresses tight junctional molecules and transporters as barrierforming cells," Journal of Cellular Physiology, vol. 217, no. 2, pp. 388-399, 2008.

[76] Y. Zhan, P. R. Krafft, T. Lekic et al., "Imatinib preserves blood-brain barrier integrity following experimental subarachnoid hemorrhage in rats," Journal of Neuroscience Research, vol. 93, no. 1, pp. 94-103, 2015.

[77] J. Yan, A. Manaenko, S. Chen et al., "Role of SCH79797 in maintaining vascular integrity in rat model of subarachnoid hemorrhage," Stroke, vol. 44, no. 5, pp. 1410-1417, 2013.

[78] O. Altay, H. Suzuki, Y. Hasegawa et al., "Isoflurane attenuates blood-brain barrier disruption in ipsilateral hemisphere after subarachnoid hemorrhage in mice," Stroke, vol. 43, no. 9, pp. 2513-2516, 2012.

[79] H. Suzuki, Y. Hasegawa, K. Kanamaru, and J. H. Zhang, "Mechanisms of osteopontin-induced stabilization of bloodbrain barrier disruption after subarachnoid hemorrhage in rats," Stroke, vol. 41, no. 8, pp. 1783-1790, 2010.

[80] Y. Chen, Y. Zhang, J. Tang et al., "Norrin protected bloodbrain barrier via frizzled- $4 / \beta$-catenin pathway after subarachnoid hemorrhage in rats," Stroke, vol. 46, no. 2, pp. 529-536, 2015.

[81] F. M. O'Farrell and D. Attwell, "A role for pericytes in coronary no-reflow," Nature Reviews. Cardiology, vol. 11, no. 7, pp. 427-432, 2014.

[82] D. M. Greif and A. Eichmann, "Vascular biology: brain vessels squeezed to death," Nature, vol. 508, no. 7494, pp. 50-51, 2014.

[83] H. Ohkuma, K. Itoh, S. Shibata, and S. Suzuki, "Morphological changes of intraparenchymal arterioles after experimental subarachnoid hemorrhage in dogs," Neurosurgery, vol. 41, no. 1, pp. 230-235, 1997, discussion 235-6.

[84] H. Johshita, N. F. Kassell, T. Sasaki, and H. Ogawa, "Impaired capillary perfusion and brain edema following experimental subarachnoid hemorrhage: a morphometric study," Journal of Neurosurgery, vol. 73, no. 3, pp. 410-417, 1990.

[85] Q. Li, Y. Chen, B. Li et al., "Hemoglobin induced NO/cGMP suppression deteriorate microcirculation via pericyte phenotype transformation after subarachnoid hemorrhage in rats," Scientific Reports, vol. 6, article 22070, 2016.

[86] I. Spokoyny, R. Raman, K. Ernstrom et al., "Pooled assessment of computed tomography interpretation by vascular neurologists in the STRokE DOC telestroke network," Journal of Stroke and Cerebrovascular Diseases, vol. 23, no. 3, pp. 511-515, 2014.

[87] B. Obermeier, R. Daneman, and R. M. Ransohoff, "Development, maintenance and disruption of the blood-brain barrier," Nature Medicine, vol. 19, no. 12, pp. 1584-1596, 2013.

[88] M. Hagedorn, M. Balke, A. Schmidt et al., "VEGF coordinates interaction of pericytes and endothelial cells during vasculogenesis and experimental angiogenesis," Developmental Dynamics, vol. 230, no. 1, pp. 23-33, 2004.

[89] S. Sinha, M. H. Hoofnagle, P. A. Kingston, M. E. McCanna, and G. K. Owens, “Transforming growth factor- $\beta 1$ signaling contributes to development of smooth muscle cells from embryonic stem cells," American Journal of Physiology. Cell Physiology, vol. 287, no. 6, pp. C1560-C1568, 2004.

[90] K. Gaengel, G. Genové, A. Armulik, and C. Betsholtz, "Endothelial-mural cell signaling in vascular development and angiogenesis," Arteriosclerosis, Thrombosis, and Vascular Biology, vol. 29, no. 5, pp. 630-638, 2009.

[91] W. Cai, H. Liu, J. Zhao et al., "Pericytes in brain injury and repair after ischemic stroke," Translational Stroke Research, vol. 8, no. 2, pp. 107-121, 2016.

[92] M. Kloc, J. Z. Kubiak, X. C. Li, and R. M. Ghobrial, "Pericytes, microvasular dysfunction, and chronic rejection," Transplantation, vol. 99, no. 4, pp. 658-667, 2015.

[93] J. F. Arboleda-Velasquez, C. N. Valdez, C. K. Marko, and P. A. D'Amore, "From pathobiology to the targeting of pericytes for the treatment of diabetic retinopathy," Current Diabetes Reports, vol. 15, no. 2, p. 573, 2015.

[94] O. V. Glinskii, V. H. Huxley, V. V. Glinskii, L. J. Rubin, and V. V. Glinsky, "Pulsed estrogen therapy prevents post-OVX porcine dura mater microvascular network weakening via a PDGF-BB-dependent mechanism," PLoS One, vol. 8, no. 12, article e82900, 2013.

[95] F. Contard, A. Sabri, M. Glukhova et al., "Arterial smooth muscle cell phenotype in stroke-prone spontaneously hypertensive rats," Hypertension, vol. 22, no. 5, pp. 665-676, 1993.

[96] J. Wu, Y. Zhang, P. Yang et al., "Recombinant osteopontin stabilizes smooth muscle cell phenotype via integrin receptor/integrin-linked kinase/Rac-1 pathway after subarachnoid hemorrhage in rats," Stroke, vol. 47, no. 5, pp. 1319-1327, 2016.

[97] M. H. Lee, B. J. Kwon, H. J. Seo et al., "Resveratrol inhibits phenotype modulation by platelet derived growth factor-bb in rat aortic smooth muscle cells," Oxidative Medicine and Cellular Longevity, vol. 2014, Article ID 572430, 9 pages, 2014.

[98] T. Miyata, H. Iizasa, Y. Sai, J. Fujii, T. Terasaki, and E. Nakashima, "Platelet-derived growth factor-BB (PDGF$\mathrm{BB}$ ) induces differentiation of bone marrow endothelial progenitor cell-derived cell line TR-BME2 into mural cells, and changes the phenotype," Journal of Cellular Physiology, vol. 204, no. 3, pp. 948-955, 2005. 
[99] P. Munot, D. E. Saunders, D. M. Milewicz et al., “A novel distinctive cerebrovascular phenotype is associated with heterozygous Arg179 ACTA2 mutations," Brain, vol. 135, no. Pt 8, pp. 2506-2514, 2012.

[100] C. K. Griswold, "A model of the physiological basis of a multivariate phenotype that is mediated by $\mathrm{Ca}^{2+}$ signaling and controlled by ryanodine receptor composition," Journal of Theoretical Biology, vol. 282, no. 1, pp. 14-22, 2011.

[101] Y. Chimori, K. Hayashi, K. Kimura et al., "Phenotype-dependent expression of cadherin $6 \mathrm{~B}$ in vascular and visceral smooth muscle cells," FEBS Letters, vol. 469, no. 1, pp. 6771,2000 .

[102] N. Henninger and M. Fisher, "Extending the time window for endovascular and pharmacological reperfusion," Translational Stroke Research, vol. 7, no. 4, pp. 284-293, 2016.

[103] L. Chazalviel, B. Haelewyn, M. Degoulet et al., "Hyperbaric oxygen increases tissue-plasminogen activator-induced thrombolysis in vitro, and reduces ischemic brain damage and edema in rats subjected to thromboembolic brain ischemia," Medical Gas Research, vol. 6, no. 2, pp. 64-69, 2016.

[104] B. Ovbiagele, J. L. Saver, S. Starkman et al., "Statin enhancement of collateralization in acute stroke," Neurology, vol. 68, no. 24, pp. 2129-2131, 2007.

[105] J. L. Lucitti, N. J. Tarte, and J. E. Faber, "Chloride intracellular channel 4 is required for maturation of the cerebral collateral circulation," American Journal of Physiology Heart and Circulatory Physiology, vol. 309, no. 7, pp. H1141-H1150, 2015.

[106] D. Chalothorn, H. Zhang, J. E. Smith, J. C. Edwards, and J. E. Faber, "Chloride intracellular channel-4 is a determinant of native collateral formation in skeletal muscle and brain," Circulation Research, vol. 105, no. 1, pp. 89-98, 2009.

[107] M. R. Harrigan, S. R. Ennis, S. E. Sullivan, and R. F. Keep, "Effects of intraventricular infusion of vascular endothelial growth factor on cerebral blood flow, edema, and infarct volume," Acta Neurochirurgica, vol. 145, no. 1, pp. 49-53, 2003.

[108] M. R. Harrigan, S. R. Ennis, T. Masada, and R. F. Keep, "Intraventricular infusion of vascular endothelial growth factor promotes cerebral angiogenesis with minimal brain edema," Neurosurgery, vol. 50, no. 3, pp. 589-598, 2002.

[109] T. Shimazu, I. Inoue, N. Araki et al., "A peroxisome proliferator-activated receptor- $\gamma$ agonist reduces infarct size in transient but not in permanent ischemia," Stroke, vol. 36, no. 2, pp. 353-359, 2005.

[110] J. Culman, M. Nguyen-Ngoc, T. Glatz, P. Gohlke, T. Herdegen, and Y. Zhao, "Treatment of rats with pioglitazone in the reperfusion phase of focal cerebral ischemia: a preclinical stroke trial," Experimental Neurology, vol. 238, no. 2, pp. 243-253, 2012.

[111] M. A. Hill, Z. Sun, L. Martinez-Lemus, and G. A. Meininger, "New technologies for dissecting the arteriolar myogenic response," Trends in Pharmacological Sciences, vol. 28, no. 7, pp. 308-315, 2007.

[112] C. Howarth, "The contribution of astrocytes to the regulation of cerebral blood flow," Frontiers in Neuroscience, vol. 8, no. 8, p. 103, 2014.

[113] D. Stephenson, T. Yin, E. B. Smalstig et al., “Transcription factor nuclear factor-kappa B is activated in neurons after focal cerebral ischemia," Journal of Cerebral Blood Flow \& Metabolism, vol. 20, no. 3, pp. 592-603, 2000.

[114] A. K. Samraj, A. H. Müller, A. S. Grell, and L. Edvinsson, "Role of unphosphorylated transcription factor STAT3 in late cerebral ischemia after subarachnoid hemorrhage," Journal of Cerebral Blood Flow \& Metabolism, vol. 34, no. 5, pp. 759763, 2014.

[115] K. Jeyaseelan, K. Y. Lim, and A. Armugam, "MicroRNA expression in the blood and brain of rats subjected to transient focal ischemia by middle cerebral artery occlusion," Stroke, vol. 39, no. 3, pp. 959-966, 2008.

[116] Y. Wang, J. Huang, Y. Ma et al., "MicroRNA-29b is a therapeutic target in cerebral ischemia associated with aquaporin 4," Journal of Cerebral Blood Flow \& Metabolism, vol. 35, no. 12, 2015.

[117] L. Zeng, J. Liu, Y. Wang et al., "MicroRNA-210 as a novel blood biomarker in acute cerebral ischemia," Frontiers in Bioscience, vol. 3, no. 4, p. 1265, 2011.

[118] K. J. Yin, Z. Deng, H. Huang et al., "miR-497 regulates neuronal death in mouse brain after transient focal cerebral ischemia," Neurobiology of Disease, vol. 38, no. 1, p. 17, 2010 .

[119] C. S. Gan, C. W. Wang, and K. S. Tan, "Circulatory microRNA-145 expression is increased in cerebral ischemia," Genetics \& Molecular Research, vol. 11, no. 1, p. 147, 2012.

[120] S. Saleem, P. D. Teal, W. B. Kleijn, T. O'Donnell, T. Witter, and Y. C. Tzeng, "Non-linear characterisation of cerebral pressure-flow dynamics in humans," PLoS One, vol. 10, no. 9, article e0139470, 2015.

[121] G. D. Mitsis, P. N. Ainslie, M. J. Poulin, P. A. Robbins, and V. Z. Marmarelis, Nonlinear Modeling of the Dynamic Effects of Arterial Pressure and Blood Gas Variations on Cerebral Blood Flow in Healthy Humans, Springer, United States of America, 2004.

[122] C. O. Tan, "Defining the characteristic relationship between arterial pressure and cerebral flow," Journal of Applied Physiology, vol. 113, no. 8, pp. 1194-1200, 2012.

[123] G. D. Mitsis, A. Mahalingam, R. Zhang, B. D. Levine, and V. Z. Marmarelis, "Nonlinear analysis of dynamic cerebral autoregulation in humans under orthostatic stress," in Engineering in Medicine and Biology Society, 2003. Proceedings of the 25th Annual International Conference of the IEEE, Cancun, Mexico, 2003.

[124] C. C. Chiu and S. J. Yeh, "Assessment of cerebral autoregulation using time-domain cross-correlation analysis," Computers in Biology \& Medicine, vol. 31, no. 6, p. 471, 2001.

[125] B. Y. Liau, S. J. Yeh, and C. C. Chiu, "Using crosscorrelation function to assess dynamic cerebral autoregulation in response to posture changes for stroke patients," Computing in Cardiology, vol. 37, no. 23, pp. 605-608, 2011.

[126] M. Chacón, C. Blanco, R. Panerai, and D. Evans, "Nonlinear modeling of dynamic cerebral autoregulation using recurrent neural networks," in 10th Iberoamerican Congress on Pattern Recognition, CIARP 2005, Havana, Cuba, November 15-18, 2005.

[127] H. Lu, R. Setiono, and H. Liu, "Effective data mining using neural networks," IEEE Transactions on Knowledge \& Data Engineering, vol. 8, no. 6, pp. 957-961, 1996.

[128] C. C. Chiu, Y. H. Hu, S. J. Yeh, and D. Y. Chou, "Classification of dynamic cerebral autoregulation in diabetics with autonomic neuropathy using support vector machine," in International Conference on Bioinformatics \& Computational 
Biology, BIOCOMP 2009, vol. 2, Las Vegas Nevada, United States of America, July 13-16, 2009.

[129] G. M. Fung, Machine Learning and Data Mining Via Mathematical Programming-Based Support Vector Machines, The University of Wisconsin-Madison, Madison, WI, USA, 2003.

[130] B. Y. Liau, S. J. Yeh, C. C. Chiu, and Y. C. Tsai, "Dynamic cerebral autoregulation assessment using chaotic analysis in diabetic autonomic neuropathy," Medical \& Biological Engineering \& Computing, vol. 46, no. 1, pp. 1-9, 2008.

[131] G. Qi, G. Chen, S. Du, Z. Chen, and Z. Yuan, "Analysis of a new chaotic system," Physica A Statistical Mechanics \& Its Applications, vol. 352, no. 2-4, pp. 295-308, 2005.

[132] A. Mcafee and E. Brynjolfsson, "Big data: the management revolution," Harvard Business Review, vol. 90, no. 10, p. 60, 2012.

[133] D. S. Liebeskind, "Big and bigger data in endovascular stroke therapy," Expert Review of Neurotherapeutics, vol. 15, pp. 335-337, 2015.

[134] K. Nishimura, "Big data visualization of acute stroke care practices using a nationwide neurosurgeon survey," Japanese Journal of Neurosurgery, vol. 24, no. 10, pp. 676683, 2015.

[135] A. Nishimura, K. Nishimura, A. Kada, K. Iihara, and J-ASPECT Study GROUP, "Status and future perspectives of utilizing big data in neurosurgical and stroke research," Neurologia Medico-Chirurgica, vol. 56, no. 11, pp. 655-663, 2016.

[136] N. P. Saeed, N. Pater, and T. G. Robinson, "Comparative overview of imaging techniques in stroke; measuring cerebral blood flow and estimating cerebral autoregulation," International Journal of Stroke, vol. 7, pp. 61-61, 2012.

[137] M. Modat, G. R. Ridgway, Z. A. Taylor et al., "Fast free-form deformation using graphics processing units," Computer Methods \& Programs in Biomedicine, vol. 98, no. 3, pp. 278-284, 2010.

[138] S. Z. Ueng, M. Lathara, S. S. Baghsorkhi, and W. H. Wen-mei, "CUDA-lite: reducing GPU programming complexity," Lecture Notes in Computer Science, vol. 8, pp. 1-15, 2008.

[139] B. Jiang, W. Dai, A. Khaliq, M. Carey, X. Zhou, and L. Zhang, "Novel 3D GPU based numerical parallel diffusion algorithms in cylindrical coordinates for health care simulation," Mathematics and Computers in Simulation, vol. 109, pp. 119, 2015.

[140] B. Jiang, A. Struthers, Z. Sun et al., "Employing graphics processing unit technology, alternating direction implicit method and domain decomposition to speed up the numerical diffusion solver for the biomedical engineering research," International Journal for Numerical Methods in Biomedical Engineering, vol. 27, no. 11, pp. 18291849, 2011.

[141] H. Peng, T. Peng, J. Wen et al., "Characterization of p38 MAPK isoforms for drug resistance study using systems biology approach," Bioinformatics, vol. 30, no. 13, pp. 18991907, 2014.

[142] L. Zhang, B. Jiang, Y. Wu et al., "Developing a multiscale, multi-resolution agent-based brain tumor model by graphics processing units," Theoretical Biology \& Medical Modelling, vol. 8, p. 46, 2011.

[143] L. Zhang, M. Qiao, H. Gao et al., "Investigation of mechanism of bone regeneration in a porous biodegradable calcium phosphate $(\mathrm{CaP})$ scaffold by a combination of a multi-scale agent-based model and experimental optimization/validation," Nanoscale, vol. 8, no. 31, p. 14877, 2016.

[144] L. Zhang, Y. Xue, B. Jiang et al., "Multiscale agent-based modelling of ovarian cancer progression under the stimulation of the STAT 3 pathway," International Journal of Data Mining and Bioinformatics, vol. 9, no. 3, pp. 235253, 2014

[145] L. Zhang and S. Zhang, "Using game theory to investigate the epigenetic control mechanisms of embryo development: comment on: "epigenetic game theory: how to compute the epigenetic control of maternal-to-zygotic transition" by Qian Wang et al," Physics of Life Reviews, vol. 20, pp. 140-142, 2017.

[146] M. Jaeger, M. Soehle, M. U. Schuhmann, D. Winkler, and J. Meixensberger, "Correlation of continuously monitored regional cerebral blood flow and brain tissue oxygen," Acta Neurochirurgica, vol. 147, no. 1, pp. 51-56, 2005, discussion 56.

[147] P. J. Sioutos, J. A. Orozco, L. P. Carter, M. E. Weinand, A. J. Hamilton, and F. C. Williams, "Continuous regional cerebral cortical blood flow monitoring in head-injured patients," Neurosurgery, vol. 36, no. 5, pp. 943-949, 1995, discussion 949-50.

[148] C. S. Robertson, S. P. Gopinath, J. C. Goodman, C. F. Contant, A. B. Valadka, and R. K. Narayan, "SjvO2 monitoring in headinjured patients," Journal of Neurotrauma, vol. 12, no. 5, pp. 891-896, 1995.

[149] M. Sheinberg, M. J. Kanter, C. S. Robertson, C. F. Contant, R. K. Narayan, and R. G. Grossman, "Continuous monitoring of jugular venous oxygen saturation in head-injured patients," Journal of Neurosurgery, vol. 76, no. 2, pp. 212217, 1992.

[150] G. K. Barcelos, Y. Tholance, S. Grousson et al., "Outcome of poor-grade subarachnoid hemorrhage as determined by biomarkers of glucose cerebral metabolism," Neurocritical Care, vol. 18, no. 2, pp. 234-244, 2013.

[151] K. Ide and N. H. Secher, "Cerebral blood flow and metabolism during exercise," Progress in Neurobiology, vol. 61, no. 4, pp. 397-414, 2000.

[152] R. Parthasarathy, M. Kate, J. L. Rempel et al., "Prognostic evaluation based on cortical vein score difference in stroke," Stroke, vol. 44, no. 10, pp. 2748-2754, 2013.

[153] E. S. Connolly Jr, A. A. Rabinstein, J. R. Carhuapoma et al., "Guidelines for the management of aneurysmal subarachnoid hemorrhage: a guideline for healthcare professionals from the American Heart Association/American Stroke Association," Stroke, vol. 43, no. 6, pp. 1711-1737, 2012.

[154] W. S. Smith, “Technology insight: recanalization with drugs and devices during acute ischemic stroke," Nature Clinical Practice Neurology, vol. 3, no. 1, pp. 45-53, 2007.

[155] P. A. Ringleb, P. D. Schellinger, C. Schranz, and W. Hacke, "Thrombolytic therapy within 3 to 6 hours after onset of ischemic stroke: useful or harmful?," Stroke, vol. 33, no. 5, pp. 1437-1441, 2002.

[156] R. Medel, S. J. Monteith, R. W. Crowley, and A. S. Dumont, "A review of therapeutic strategies for the management of cerebral venous sinus thrombosis," Neurosurgical Focus, vol. 27, no. 5, article E6, 2009.

[157] J. M. Simard, E. F. Aldrich, D. Schreibman, R. F. James, A. Polifka, and N. Beaty, "Low-dose intravenous heparin infusion in patients with aneurysmal subarachnoid 
hemorrhage: a preliminary assessment," Journal of Neurosurgery, vol. 119, no. 6, pp. 1611-1619, 2013.

[158] P. Zamboni, A. Bertolotto, P. Boldrini et al., "Efficacy and safety of venous angioplasty of the extracranial veins for multiple sclerosis. Brave dreams study (brain venous drainage exploited against multiple sclerosis): study protocol for a randomized controlled trial," Trials, vol. 13, p. 183, 2012.

[159] R. Burger, D. Duncker, N. Uzma, and V. Rohde, "Decompressive craniotomy: durotomy instead of duroplasty to reduce prolonged ICP elevation," Acta Neurochirurgica Supplement, vol. 102, pp. 93-97, 2008. 

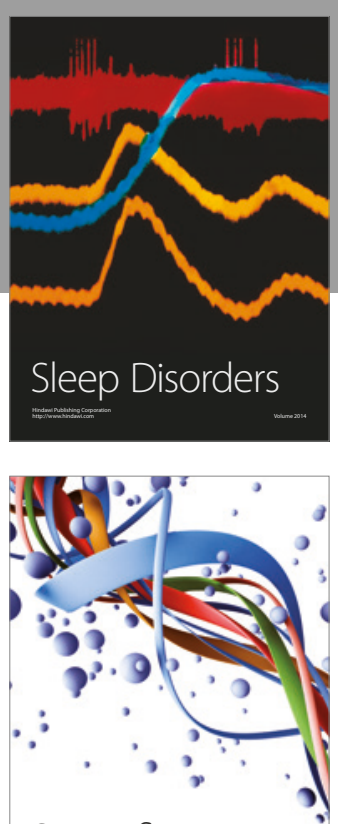

Scientifica
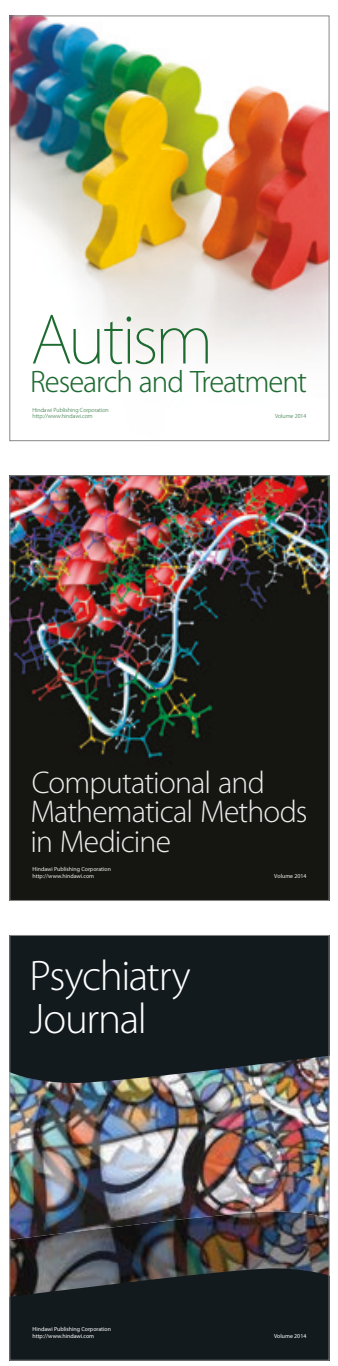
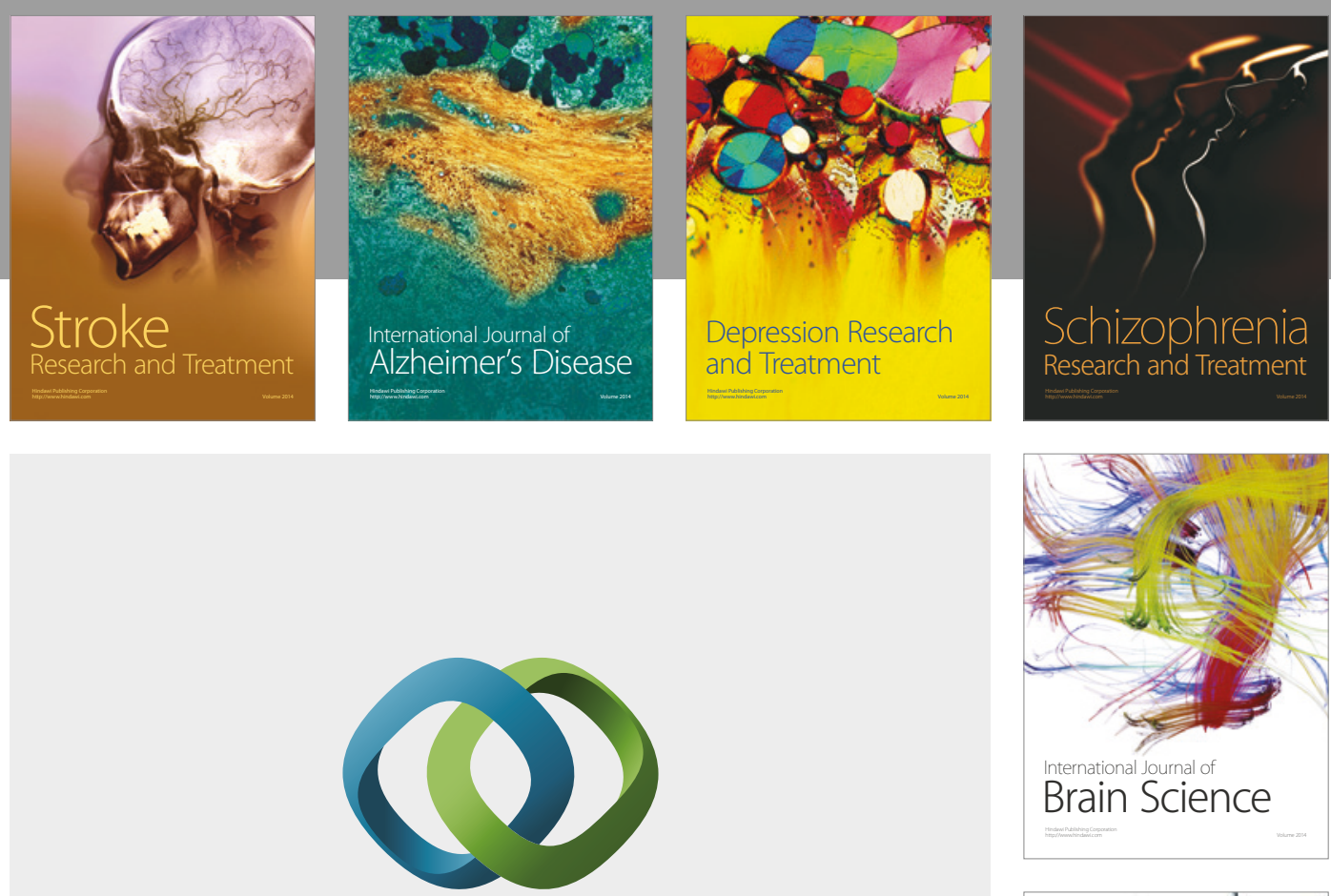

\section{Hindawi}

Submit your manuscripts at

https://www.hindawi.com
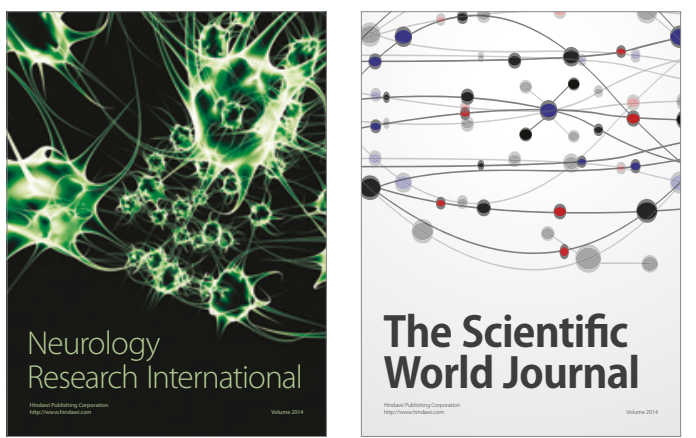

The Scientific World Journal

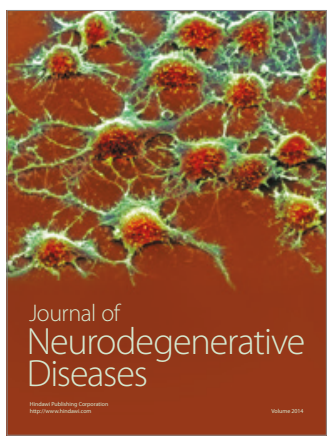

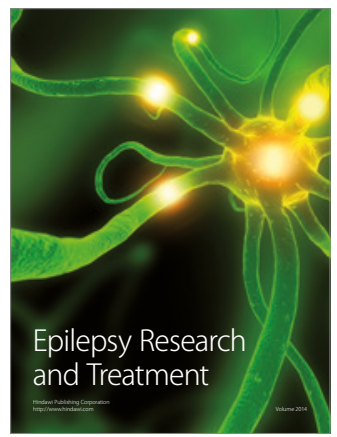

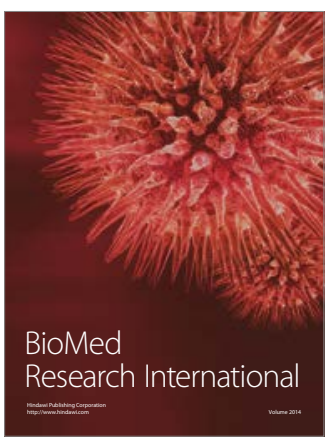



Brain Science

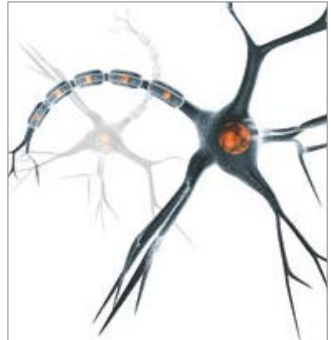

Neural Plasticity
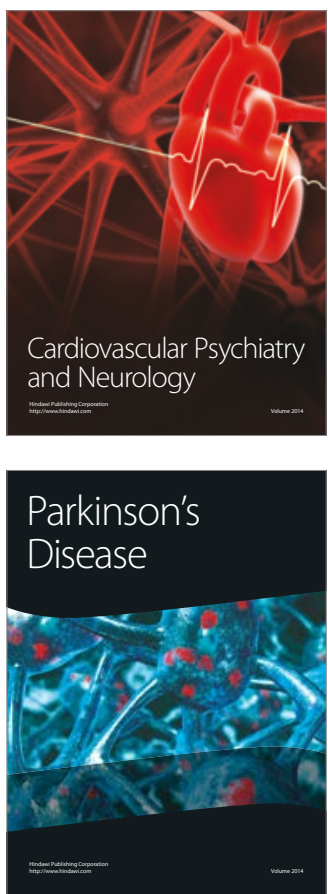